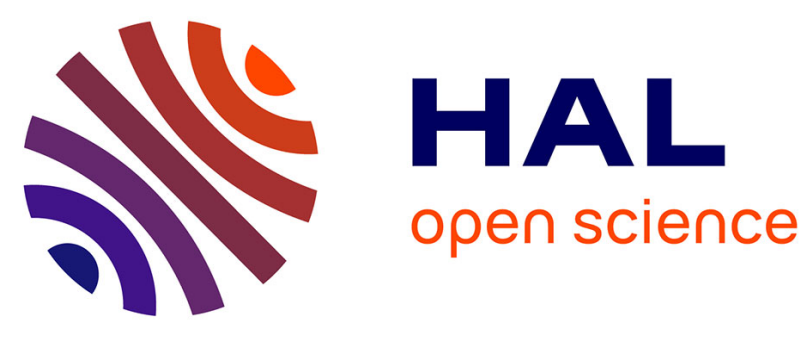

\title{
ST-Segment Elevation Myocardial Infarction Following Transcatheter Aortic Valve Replacement
}

Laurent Faroux, Thibault Lhermusier, Flavien Vincent, Luis Nombela-Franco,

Didier Tchétché, Marco Barbanti, Mohamed Abdel-Wahab, Stephan

Windecker, Vincent Auffret, Diego Carter Campanha-Borges, et al.

\section{To cite this version:}

Laurent Faroux, Thibault Lhermusier, Flavien Vincent, Luis Nombela-Franco, Didier Tchétché, et al.. ST-Segment Elevation Myocardial Infarction Following Transcatheter Aortic Valve Replacement. Journal of the American College of Cardiology, 2021, 77 (17), pp.2187-2199. 10.1016/j.jacc.2021.03.014 . hal-03213608

\section{HAL Id: hal-03213608 \\ https://hal.science/hal-03213608}

Submitted on 30 Apr 2021

HAL is a multi-disciplinary open access archive for the deposit and dissemination of scientific research documents, whether they are published or not. The documents may come from teaching and research institutions in France or abroad, or from public or private research centers.
L'archive ouverte pluridisciplinaire HAL, est destinée au dépôt et à la diffusion de documents scientifiques de niveau recherche, publiés ou non, émanant des établissements d'enseignement et de recherche français ou étrangers, des laboratoires publics ou privés. 


\section{ST-Segment Elevation Myocardial Infarction Following Transcatheter Aortic Valve Replacement}

Laurent Faroux, MD, ${ }^{a}$ Thibault Lhermusier, MD, ${ }^{\mathrm{b}}$ Flavien Vincent, MD, ${ }^{\mathrm{c}}$ Luis Nombela-Franco, MD, PHD, ${ }^{\mathrm{d}}$ Didier Tchétché, MD, ${ }^{\mathrm{e}}$ Marco Barbanti, MD, ${ }^{\mathrm{f}}$ Mohamed Abdel-Wahab, MD, ${ }^{\mathrm{g}}$ Stephan Windecker, MD, ${ }^{\mathrm{h}}$ Vincent Auffret, MD, ${ }^{\mathrm{i}}$ Diego Carter Campanha-Borges, MD, ${ }^{\mathrm{j}}$ Quentin Fischer, MD, ${ }^{\mathrm{k}}$ Erika Muñoz-Garcia, MD, Ramiro Trillo-Nouche, MD, ${ }^{\mathrm{m}}$ Troels Jorgensen, $\mathrm{MD},{ }^{\mathrm{n}}$ Vicens Serra, MD, ${ }^{\circ}$ Stefan Toggweiler, MD, ${ }^{\mathrm{p}}$ Giuseppe Tarantini, MD, ${ }^{\mathrm{q}}$ Francesco Saia, MD, ${ }^{\mathrm{r}}$ Eric Durand, MD, ${ }^{\mathrm{s}}$ Pierre Donaint, MD, ${ }^{\mathrm{t}}$ Enrique Gutierrez-Ibanes, MD, ${ }^{\mathrm{u}}$ Harindra C. Wijeysundera, MD, ${ }^{\mathrm{v}}$ Gabriela Veiga, MD, ${ }^{\mathrm{w}}$ Giuseppe Patti, MD, ${ }^{\mathrm{x}}$ Fabrizio D'Ascenzo, MD, ${ }^{y}$ Raul Moreno, MD, ${ }^{z}$ Christian Hengstenberg, MD, ${ }^{\text {aa }}$ Chekrallah Chamandi, MD, ${ }^{\text {bb }}$ Lluis Asmarats, MD, PHD, ${ }^{c c}$ Rosana Hernandez-Antolin, MD, ${ }^{\text {dd }}$ Joan Antoni Gomez-Hospital, MD, ${ }^{\text {ee }}$ Juan Gabriel Cordoba-Soriano, MD, ${ }^{\text {ff }}$ Uri Landes, MD, ${ }^{\text {gg }}$ Victor Alfonso Jimenez-Diaz, MD, ${ }^{\text {hh }}$ Ignacio Cruz-Gonzalez, MD, ${ }^{\mathrm{ii}}$ Mohammed Nejjari, MD,j ${ }^{\mathrm{jj}}$ François Roubille, MD, PHD, ${ }^{\mathrm{kk}}$ Éric Van Belle, MD, PHD, German Armijo, MD, ${ }^{\mathrm{d}}$ Saifullah Siddiqui, MD, ${ }^{\mathrm{e}}$ Giuliano Costa, MD, ${ }^{\mathrm{f}}$ Sameh Elsaify, MD, ${ }^{\mathrm{g}}$ Thomas Pilgrim, MD, ${ }^{\mathrm{h}}$ Hervé le Breton, MD, ${ }^{\mathrm{i}}$ Marina Urena, MD, ${ }^{\mathrm{k}}$ Antonio Jesus Muñoz-Garcia, MD, ${ }^{1}$ Lars Sondergaard, MD, ${ }^{\mathrm{n}}$ Montserrat Bach-Oller, MD, ${ }^{\circ}$ Chiara Fraccaro, MD, ${ }^{\mathrm{q}}$ Hélène Eltchaninoff, MD, ${ }^{\mathrm{s}}$ Damien Metz, MD, ${ }^{\mathrm{t}}$ Maria Tamargo, MD, ${ }^{\mathrm{u}}$ Victor Fradejas-Sastre, RN, ${ }^{\mathrm{w}}$ Andrea Rognoni, MD, ${ }^{\mathrm{x}}$ Francesco Bruno, MD, ${ }^{\mathrm{y}}$ Georg Goliasch, MD, ${ }^{\text {aa }}$ Marcelo Santaló-Corcoy, MD, ${ }^{c c}$ Jesus Jimenez-Mazuecos, MD, ${ }^{\text {ff }}$ John G. Webb, MD,gg Guillem Muntané-Carol, MD, ${ }^{a}$ Jean-Michal Paradis, MD, ${ }^{\mathrm{a}}$ Antonio Mangieri, MD, ${ }^{\mathrm{ll}}$ Henrique Barbosa Ribeiro, MD, Francisco Campelo-Parada, MD, ${ }^{\mathrm{b}}$ Josep Rodés-Cabau, $\mathrm{MD}, \mathrm{PHD}^{\mathrm{a}, \mathrm{mm}}$

\section{ABSTRACT}

BACKGROUND Among patients with acute coronary syndrome following transcatheter aortic valve replacement (TAVR), those presenting with ST-segment elevation myocardial infarction (STEMI) are at highest risk.

OBJECTIVES The goal of this study was to determine the clinical characteristics, management, and outcomes of STEMI after TAVR.

METHODS This was a multicenter study including 118 patients presenting with STEMI at a median of 255 days (interquartile range: 9 to 680 days) after TAVR. Procedural features of STEMI after TAVR managed with primary percutaneous coronary intervention (PCI) were compared with all-comer STEMI: 439 non-TAVR patients who had primary PCI within the 2 weeks before and after each post-TAVR STEMI case in 5 participating centers from different countries.

RESULTS Median door-to-balloon time was higher in TAVR patients (40 min [interquartile range: 25 to $57 \mathrm{~min}$ ] vs. $30 \mathrm{~min}$ [interquartile range: 25 to $35 \mathrm{~min}$ ]; $\mathrm{p}=0.003$ ). Procedural time, fluoroscopy time, dose-area product, and contrast volume were also higher in TAVR patients ( $\mathrm{p}<0.01$ for all). $\mathrm{PCI}$ failure occurred more frequently in patients with previous TAVR $(16.5 \%$ vs. $3.9 \% ; p<0.001)$, including 5 patients in whom the culprit lesion was not revascularized owing to coronary ostia cannulation failure. In-hospital and late (median of 7 months [interquartile range: 1 to 21 months]) mortality rates were $25.4 \%$ and $42.4 \%$, respectively (20.6\% and $38.2 \%$ in primary PCl patients), and estimated glomerular filtration rate $<60 \mathrm{ml} / \mathrm{min}$ (hazard ratio [HR]: $3.02 ; 95 \%$ confidence interval [Cl]: 1.42 to $6.43 ; p=0.004$ ), Killip class $\geq 2$ (HR: 2.74 ; 95\% Cl: 1.37 to $5.49 ; \mathrm{p}=0.004$ ), and $\mathrm{PCl}$ failure (HR: $3.23 ; 95 \% \mathrm{Cl}: 1.42$ to $7.31 ; \mathrm{p}=0.005$ ) determined an increased risk. CONCLUSIONS STEMI after TAVR was associated with very high in-hospital and mid-term mortality. Longer door-toballoon times and a higher $\mathrm{PCl}$ failure rate were observed in TAVR patients, partially due to coronary access issues specific to the TAVR population, and this was associated with poorer outcomes. (J Am Coll Cardiol 2021;77:2187-99)

(c) 2021 by the American College of Cardiology Foundation.

From the ${ }^{a}$ Quebec Heart and Lung Institute, Laval University, Québec City, Québec, Canada; ${ }^{b}$ Rangueil University Hospital, Toulouse, France; ${ }^{\mathrm{C}} \mathrm{CHU}$ Lille, Institut Coeur et Poumon, Cardiology, Department of Interventional Cardiology for Coronary, Valves and Structural Heart Diseases, Inserm U1011, Institut Pasteur de Lille, EGID, Université de Lille, Lille, France; ${ }^{\mathrm{d} C}$ Cardiovascular Institute, Hospital Clinico San Carlos, IdISSC, Madrid, Spain; ${ }^{\mathrm{e}}$ Clinique Pasteur, Toulouse, France; ${ }^{\mathrm{f}}$ A.O.U. Policlinico 


\section{ABBREVIATIONS AND ACRONYMS}

ACS = acute coronary

syndrome

CABG = coronary artery bypass grafting

$C A D=$ coronary artery disease

MACCE $=$ major adverse

cardiovascular or

cerebrovascular event

$\mathrm{PCl}=$ percutaneous coronary

intervention

RCA = right coronary artery

STEMI = ST-segment elevation

myocardial infarction

TAVR = transcatheter aortic

valve replacement
A

bout $50 \%$ of transcatheter aortic valve replacement (TAVR) recipients exhibit some degree of coronary artery disease (CAD), with one-half of them having multivessel disease (1). Acute coronary syndrome (ACS) events after TAVR exhibit some features different from those occurring in the non-TAVR population, including a much lower proportion of STsegment elevation myocardial infarction (STEMI) ( $1 \%$ to $8 \%$ of all post-TAVR ACS) (2-4) and an increased risk of death and major adverse cardiovascular and cerebrovascular event (MACCE) in STEMI patients (compared with other ACS types) $(3,4)$. The advanced age of TAVR recipients (5) along with the high incidence of non-STEMI patients (type 2) after TAVR $(2,3)$ likely explain the shift in STEMI proportion between non-TAVR and TAVR patients. Also, the poor prognosis of post-TAVR STEMI could be related to patients' characteristics (high comorbidity burden) along with the involvement of pathophysiologic mechanisms other than atherothrombosis (impaired coronary flow, leaflet thrombosis, coronary embolism, late valve migration) (1). In addition, the potential interaction between the transcatheter heart valve and the coronary ostia $(1,6,7)$ may be associated with a significant delay or even preclude primary percutaneous coronary intervention (PCI), which would likely have a major negative impact on patients' prognosis. However, to date no study has specifically evaluated this high-risk population and most aspects of post-TAVR STEMI remain unknown. Therefore, the present study sought to determine the clinical characteristics, management, and outcomes of STEMI after TAVR.

\section{METHODS}

This was a multicenter international study including 118 patients presenting with STEMI after TAVR from 38 centers (out of 42,252 TAVR recipients, cumulative incidence of $0.3 \%$ ). Mechanical coronary obstruction leading to STEMI during the TAVR procedure was not included in this analysis. CAD was defined as prior PCI, coronary artery bypass grafting (CABG), or myocardial infarction, or presence of coronary stenosis $\geq 50 \%$. All patients but 1 underwent coronary angiography before TAVR, with CAD ruled out by preprocedural electrocardiography (ECG)-gated cardiac computed tomography in the remaining patient. PreTAVR PCI was performed if judged necessary by the local heart team. Chronic total occlusions and lesions that were either very distal or located in small vessels $(<2 \mathrm{~mm})$ were generally medically managed (8). When all significant lesions in vessels of $>2 \mathrm{~mm}$ in diameter had been successfully treated with either CABG or PCI, revascularization was considered complete. TAVR indication, valve type, and approach were determined by the heart team of each center.

"G. Rodolico-San Marco", Catania, Italy; ' Bern, Switzerland; i'Univ Rennes, CHU Rennes, Inserm, LTSI - UMR1099, Rennes, France; 'Instituto do Coração (InCor), Heart Institute, University of Sao Paulo, Sao Paulo, Brazil; ' Assistance Publique-Hôpitaux de Paris, Bichat Hospital, Paris, France; ${ }^{1}$ Hospital Universitario Virgen de la Victoria, Málaga, Centro de Investigación Biomédica en Red Enfermedades Cardiovaculares, Spain; ${ }^{\mathrm{m}}$ Hospital Universitario de Santiago de Compostela, Santiago de Compostela, Spain; ${ }^{\mathrm{n}}$ Rigshospitalet, University of Copenhagen, Copenhagen, Denmark; ${ }^{\circ}$ Hospital Universitari Vall d’Hebron, Barcelona, Spain; ${ }^{\mathrm{p}}$ Heart Center Lucerne, Lucerne, Switzerland; 'Padova Univesity Hospital, Padova, Italy; 'Institute of Cardiology, Policlinico S. Orsola-Malpighi, Bologna, Italy; ${ }^{\mathrm{s}}$ Normandie Univ, UNIROUEN, U1096, CHU Rouen, Department of Cardiology, FHU CARNAVAL, F-76000, Rouen, France; ${ }^{\mathrm{t} C e n t r e}$ Hospitalier Universitaire de Reims, Service de Cardiologie, Reims, France; ${ }^{u}$ Hospital Gregorio Maranon, Madrid, Spain; 'Sunnybrook Health Sciences Centre, Toronto, Ontario, Canada; ${ }^{\mathrm{w}}$ Hospital Universitario Marqués de Valdecilla, Santander, Spain; ${ }^{\mathrm{x}} \mathrm{Maggiore}$ della Carità Hospital, University of Eastern Piedmont, Novara, Italy; ${ }^{y}$ Division of Cardiology, Department of Medical Science, Citta’ della

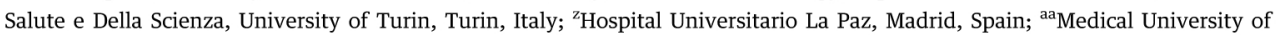
Vienna, Vienna, Austria; ${ }^{b}$ Hôpital Européen Georges Pompidou, Paris, France; ${ }^{c c}$ Hospital Santa Creu i Sant Pau, Barcelona, Spain; ${ }^{\mathrm{dd}}$ Hospital Universitario Ramón y Cajal, Madrid, Spain; ${ }^{\mathrm{ee}}$ Hospital Universitario Bellvitge, Barcelona, Spain; ${ }^{\mathrm{ff}}$ Hospital Universitario de Albacete, Albacete, Spain; ${ }^{\mathrm{g}} \mathrm{S}$ St. Paul's Hospital, Vancouver, British Columbia, Canada; ${ }^{\mathrm{h} h}$ Hospital Universitario Alvaro Cunqueiro, Vigo, Spain; ii University Hospital Salamanca, Centro de Investigación Biomédica en Red Enfermedades Cardiovaculares, Instituto de Investigación Biomédica de Salamanca, Salamanca, Spain; ${ }^{\mathrm{j} j}$ Centre Cardiologique du Nord, Saint-Denis, France; ${ }^{k k}$ PhyMedExp, Université de Montpellier, INSERM, CNRS, Cardiology Department, INI-CRT, CHU de Montpellier, France; ${ }^{11}$ Invasive Cardiology Unit, Humanitas Clinical and Research Center, IRCCS, Rozzano, Milan, Italy and Department of Biomedical Sciences, Humanitas University, Pieve Emanuele, Milan, Italy; and the ${ }^{\mathrm{mm}}$ Hospital Clínic de Barcelona, Barcelona, Spain. Luis Gruberg, MD, served as Guest Associate Editor for this paper. Javed Butler, MD, MPH, MBA, served as Guest Editor-in-Chief for this paper.

The authors attest they are in compliance with human studies committees and animal welfare regulations of the authors' institutions and Food and Drug Administration guidelines, including patient consent where appropriate. 
Post-TAVR clinical outcomes were defined according to Valve Academic Research Consortium 2 criteria (9). Data were collected in accordance with the ethics committee of each participating center, and all patients provided signed informed consent for the procedures.

In accordance with the Fourth Universal Definition of Myocardial Infarction (10), clinical symptoms and ECG changes compatible with myocardial ischemia were taken into consideration for the diagnosis of STEMI. STEMI management was tailored by clinical judgment of the treating physician. Definite coronary embolism corresponded to the combination of angiographic evidence of coronary embolism (filling defect or abrupt occlusion in an artery without significant atherosclerosis) in addition to a probable embolic source (recent TAVR procedure, infective endocarditis, valve thrombosis, clot in the left atrial appendage), whereas possible coronary embolism corresponded to a STEMI without angiographic lesion at the time of coronary angiography associated with a probable embolic source (11). PCI failure was defined as a final diameter stenosis $>30 \%$ or a post-dilation Thrombosis in Myocardial Infarction flow grade o or 1. Post-STEMI clinical outcomes were recorded and included allcause death, MI, and stroke. MACCEs were defined as death, MI, or stroke. A total of 22 patients included in this study had already been included in a previous global post-TAVR ACS study not focusing on the specific characteristics of STEMI patients (3).

PRIMARY PCI COHORT SUBANALYSIS. The procedural characteristics of patients with post-TAVR STEMI who had primary PCI $(n=102)$ were compared with a group of all-comer (non-TAVR) primary PCI patients (control cohort). For this purpose, data from all STEMI patients (without prior TAVR) managed with primary PCI within the 15 days before and after each post-TAVR STEMI case in 5 highvolume centers from different countries (1 center per country) were also included. A total of $439 \mathrm{pa}-$ tients were included in this control cohort.

STATISTICAL ANALYSIS. Categoric variables were expressed as $n(\%)$ and continuous variables as mean \pm SD or median (interquartile range [IQR]). Categoric variables were compared by means of chi-square test or Fisher exact test, as appropriate. Numeric variables were compared with the use of Student's $t$-test or Mann-Whitney nonparametric $U$ test according to their distribution (assessed by the KolmogorovSmirnov test). Survival curves for time-to-event rates were performed by means of Kaplan-Meier estimates. The factors associated with mortality after post-TAVR STEMI in the primary PCI cohort were

\begin{tabular}{|c|c|}
\hline \multicolumn{2}{|l|}{ Baseline variables } \\
\hline Age, yrs & $80.3 \pm 7.7$ \\
\hline Female & $59(50.0)$ \\
\hline BMI, $\mathrm{kg} / \mathrm{m}^{2}$ & $28.1 \pm 5.5$ \\
\hline Diabetes mellitus & $41(34.7)$ \\
\hline Hypertension & $100(84.7)$ \\
\hline Dyslipidemia & $68(57.6)$ \\
\hline Current smoking & $14(11.9)$ \\
\hline Atrial fibrillation & $34(28.8)$ \\
\hline COPD & $17(14.4)$ \\
\hline eGFR, ml/min & $56.5 \pm 24.9$ \\
\hline Previous CAD & $82(69.5)$ \\
\hline Previous MI & $34(28.8)$ \\
\hline Previous CABG & $15(12.7)$ \\
\hline Previous PAD & $24(20.3)$ \\
\hline LVEF, \% & $54.6 \pm 13.0$ \\
\hline AV gradient, $\mathrm{mm} \mathrm{Hg}$ & $42.1 \pm 14.7$ \\
\hline AV area, $\mathrm{cm}^{2}$ & $0.7 \pm 0.2$ \\
\hline Logistic EuroSCORE, \% & $15.9 \pm 11.7$ \\
\hline STS-PROM, \% & $5.6 \pm 4.1$ \\
\hline \multicolumn{2}{|l|}{ Pre-TAVR coronary angiography } \\
\hline \multicolumn{2}{|c|}{ Coronary artery disease, vessels: } \\
\hline 0 & $41(34.7)$ \\
\hline 1 & $27(22.9)$ \\
\hline 2 & $25(21.2)$ \\
\hline 3 & $25(21.2)$ \\
\hline $\mathrm{PCl}$ & $46(39.0)$ \\
\hline Complete revascularization & $70(59.3)$ \\
\hline \multicolumn{2}{|l|}{ Procedural characteristics } \\
\hline Transfemoral approach & $103(87.3)$ \\
\hline \multicolumn{2}{|l|}{ Prosthesis type } \\
\hline \multicolumn{2}{|l|}{ Balloon-expandable } \\
\hline Sapien/Sapien XT & $25(21.2)$ \\
\hline Sapien 3 & 27 (22.9) \\
\hline Inovare & $1(0.8)$ \\
\hline \multicolumn{2}{|l|}{ Self-expanding } \\
\hline CoreValve & $34(28.8)$ \\
\hline Evolut R/Pro & $24(20.3)$ \\
\hline Portico & $1(0.8)$ \\
\hline Acurate neo & $4(3.4)$ \\
\hline Centera & $1(0.8)$ \\
\hline \multicolumn{2}{|l|}{ Mechanically expandable } \\
\hline Lotus & $1(0.8)$ \\
\hline Valve-in-valve & $8(6.8)$ \\
\hline \multicolumn{2}{|c|}{ Antithrombotic medication at discharge: } \\
\hline None & $2(1.7)$ \\
\hline SAPT & $20(17.0)$ \\
\hline DAPT & $71(60.1)$ \\
\hline $\mathrm{OAC}$ & $5(4.2)$ \\
\hline $\mathrm{OAC}+$ antiplatelet & $20(17.0)$ \\
\hline
\end{tabular}

Values are mean $\pm S D$ or $\mathbf{n}(\%)$.

$\mathrm{AV}=$ aortic valve; $\mathrm{BMI}=$ body mass index; $\mathrm{CABG}=$ coronary artery bypass grafting; $C A D=$ coronary artery disease $; C O P D=$ chronic obstructive pulmonary disease; DAPT $=$ dual antiplatelet therapy; $\mathrm{eGFR}=$ estimated glomerular filtration rate; $\mathrm{LVEF}=$ left ventricular ejection fraction; $\mathrm{MI}=$ myocardial infarction; $\mathrm{OAC}=$ oral anticoagulant; $\mathrm{PAD}=$ peripheral artery disease $\mathrm{PCI}=$ percutaneous coronary intervention; SAPT = single-antiplatelet therapy; STS-PROM = Society of Thoracic Surgeons Predicted Risk of Mortality; TAVR = transcatheter aortic valve replacement. 
determined with the use of a univariable Cox regression model. The proportional hazard assumption was tested by plotting log-minus-log survival. Variables with $\mathrm{p} \leq 0.10$ on univariable analysis were entered into a multivariable Cox regression with stepwise selection (backward elimination). Statistical analyses were performed with SAS version 9.4 (SAS Institute, Cary, North Carolina) and Prism version 8.1.2 (GraphPad Software, San Diego, California).

\section{RESULTS}

STUDY POPULATION. The baseline and TAVR characteristics of the study population are presented in Table 1. The mean age of the patients was $80.3 \pm 7.7$ years, with $50.0 \%$ men and an overall mean Society of Thoracic Surgeons Predicted Risk of Mortality of $5.6 \pm$ 4.1\%. A total of 82 patients (69.5\%) had prior CAD, and 15 patients (12.7\%) had undergone CABG. PreTAVR coronary angiography did not find any significant lesion in 41 patients (34.7\%), and multivessel disease was present in 50 patients (42.4\%). Pre-TAVR PCI was performed in 46 patients (39.0\%), and complete revascularization was achieved in 70 patients (59.3\%). Most TAVR procedures (87.3\%) were performed through a transfemoral approach, and selfexpanding, balloon-expandable, and mechanicallyexpandable valves were implanted in $54.2 \%$, $44.9 \%$, and $0.8 \%$ of patients, respectively. A total of 8 valvein-valve procedures were included (CoreValve/Evolut system: 6 cases; SAPIEN XT/3: 2 cases). Overall, the rates of stroke, major vascular complications, and life-threatening bleeding after TAVR were, respectively, $5.1 \%, 9.3 \%$, and $4.2 \%$. At discharge, $60.1 \%$ of patients were on dual antiplatelet therapy, $21.2 \%$ on oral anticoagulant, and $17.0 \%$ on single-antiplatelet therapy, and $1.7 \%$ did not receive any antithrombotic medication.

CLINICAL CHARACTERISTICS OF STEMI AFTER TAVR. The median delay between TAVR and STEMI was 255 days (IQR: 9 to 680 days) after TAVR. A total of 41 STEMIs (34.7\%) occurred during the month following the TAVR procedure. Clinical characteristics of the post-TAVR STEMIs are summarized in Table 2. ECG findings revealed an anterior, inferior, and lateral STEMI in $35.6 \%, 32.2 \%$, and $5.9 \%$ of cases, respectively. The median time from symptom onset to hospital arrival was $130 \mathrm{~min}$ (IQR: 60 to $260 \mathrm{~min}$ ). A total of 55 patients $(46.6 \%)$ presented with signs of congestive heart failure at admission, including 21 patients (17.8\%) in cardiogenic shock. Initial presentation was cardiac arrest in 13 patients (11.0\%). Clopidogrel was used as $\mathrm{P}_{2} \mathrm{Y}_{12}$-inhibitor in most cases
TABLE 2 Clinical Characteristics, Management, and In-Hospital Outcomes of STEMI After TAVR $(\mathbf{N}=118)$

Clinical characteristics

Time from symptom onset to hospital arrival, min $130(60-260)$ ECG findings

Anterior

$42(35.6)$

Inferior

Lateral

LBBB

Other

Killip class

1

2

3

4

38 (32.2)

7 (5.9)

$11(9.3)$

20 (16.9)

63 (53.4)

27 (22.9)

7 (5.9)

21 (17.8)

Cardiac arrest at admission

13 (11.0)

LVEF, \%

$44.7 \pm 13.9$

Antithrombotic medication before STEMI

None

$2(1.7)$

SAPT

DAPT

53 (44.9)

OAC

$36(30.5)$

$\mathrm{OAC}+$ antiplatelet

$10(8.5)$

$17(14.4)$

Management

STEMI management

Pre-hospital thrombolysis $1(0.9)$

Primary PCI

$102(86.4)$

Noninvasive strategy

15 (12.7)

$\mathrm{P}_{2} \mathrm{Y}_{12}$ inhibitor

Clopidogrel

66 (55.9)

Prasugrel

$12(10.1)$

Ticagrelor

$20(17.0)$

None

$20(17.0)$

Anticoagulant

Unfractionated heparin

91 (77.1)

Enoxaparin

$3(2.5)$

Bivalirudin

$4(3.4)$

None

$20(17.0)$

GPIIb/Illa inhibitor

8 (6.8)

Coronary angiogram

$103(87.3)$

Circulatory assist device

IAPB

0 (0.0)

ECMO

2 (1.7)

In-hospital outcomes

Death

$30(25.4)$

Stroke

8 (6.8)

Atrial fibrillation

$7(5.9)$

Acute kidney injury

15 (12.7)

Antithrombotic medication at discharge

None

SAPT

$3(3.4)$

DAPT

$55(62.5)$

OAC

1 (1.1)

$\mathrm{OAC}+$ antiplatelet

$28(31.8)$

Values are median (interquartile range), $\mathrm{n}(\%)$, or mean \pm SD.

ECG = electrocardiography; ECMO = extracorporeal membrane oxygenation; $\mathrm{GP}=$ glycoprotein; IABP = intra-aortic balloon pump; LBBB = left bundle branch block; STEMI = ST-segment elevation myocardial infarction; other abbreviations as in Table 1. 


\begin{tabular}{|c|c|c|c|c|c|c|}
\hline Patient & Age, yrs & Sex & Device & Time Since TAVR, days & Reason Why No CA Was Performed & In-Hospital Death \\
\hline \#1 & 71 & Female & Sapien XT & 569 & Sudden death with resuscitation failure & Yes \\
\hline \#2 & 84 & Female & Sapien XT & 1,391 & Advanced age, late presentation & No \\
\hline$\# 3$ & 70 & Female & Sapien 3 & 12 & Sudden death with resuscitation failure & Yes \\
\hline$\# 4$ & 88 & Male & CoreValve & 680 & Frail patient & No \\
\hline \#5 & 78 & Female & CoreValve & 256 & Late presentation & No \\
\hline \#6 & 55 & Male & Sapien XT & 3 & $\begin{array}{l}\text { Transient STEMI and no significant coronary lesion } \\
\text { on pre-TAVR coronary angiography }\end{array}$ & No \\
\hline$\# 7$ & 86 & Female & CoreValve & 847 & $\begin{array}{l}\text { Advanced age, known severe CAD unsuitable for } \\
\text { PCI, cardiogenic shock and complete AVB at } \\
\text { presentation }\end{array}$ & Yes \\
\hline \#8 & 81 & Female & Sapien 3 & 254 & $\begin{array}{l}\text { Hospitalized for hip fracture; while waiting for } \\
\text { surgery, STEMI that quickly led to death }\end{array}$ & Yes \\
\hline$\# 9$ & 80 & Male & Sapien & 9 & $\begin{array}{l}\text { Late presentation, hospitalized in a non-PCl-capable } \\
\text { center, known severe CAD unsuitable for } \mathrm{PCl}\end{array}$ & Yes \\
\hline$\# 10$ & 82 & Female & CoreValve & 125 & Late presentation & Yes \\
\hline \#11 & 79 & Female & Evolut & 0 & Takotsubo suspicion & No \\
\hline$\# 12$ & 82 & Male & Sapien XT & 1,783 & Late presentation and acute kidney injury & No \\
\hline$\# 13$ & 85 & Female & CoreValve & 334 & Extreme frailty and pulmonary infection & Yes \\
\hline \#14 & 85 & Female & CoreValve & 655 & Sudden death with resuscitation failure & Yes \\
\hline \#15 & 75 & Female & Evolut & 1,291 & Sudden death with resuscitation failure & Yes \\
\hline
\end{tabular}

(55.9\%), and glycoprotein IIb/IIIa inhibitors were used in 8 patients (6.8\%). A total of 102 patients (86.4\%) were managed with primary PCI, 1 patient (0.9\%) received pre-hospital thrombolysis, and 15 patients $(12.7 \%)$ were managed medically. Rates of in-hospital mortality, stroke, and acute kidney injury were $25.4 \%, 6.8 \%$, and $12.7 \%$, respectively. At discharge, most patients received dual antiplatelet therapy (62.5\%) or a combination of oral anticoagulant and antiplatelet (31.8\%). Inhospital mortality was $20.6 \%$ in the subpopulation of patients managed with primary PCI, and $5.9 \%$ and $13.7 \%$ of patients complicated with stroke and acute kidney injury, respectively. Individual data from the 15 patients presenting with STEMI after TAVR who did not undergo coronary angiography are presented in Table 3. Among them, 9 patients (60.0\%) died in hospital. Four patients presented cardiac arrest with resuscitation failure, 2 patients had a late presentation of STEMI, 1 patient was deemed to be extremely frail, 1 patient with advanced age and known CAD unsuitable for PCI presented with STEMI complicated with cardiogenic shock and complete atrioventricular block, and 1 patient was hospitalized for hip fracture and presented with STEMI with very rapid deterioration and death. The 6 remaining STEMIs following TAVR did not undergo coronary angiography owing to advanced age, frailty, late presentation, takotsubo suspicion, and transient STEMI without significant coronary lesion on pre-TAVR coronary angiography.

PROCEDURAL FEATURES OF STEMI PATIENTS MANAGED WITH PRIMARY PCI. Comparison of baseline variables and clinical characteristics of postTAVR STEMI versus STEMI without prior TAVR are presented in Table 4. Compared with the control cohort, TAVR patients were older $(80.7 \pm 7.6$ years vs. $64.1 \pm 12.7$ years; $\mathrm{p}<0.001)$ and exhibited a much higher burden of comorbidities, with higher rates of diabetes mellitus ( $31.4 \%$ vs. $16.6 \%$; p < 0.001), hypertension (83.3\% vs. 50.8\%; p < 0.001), prior CAD (69.6\% vs. $12.5 \%$; p < 0.001$)$, and prior CABG $(13.7 \%$ vs. $1.1 \% ; \mathrm{p}<0.001)$. Table 5 presents the comparison of procedural characteristics of patients with and without prior TAVR. The proportion of coronary angiography performed through a femoral access was much higher in patients with prior TAVR $(47.1 \%$ vs. 9.6\%; $\mathrm{p}<0.001)$. A switch from radial to femoral access occurred in 9 patients $(8.8 \%)$ with post-TAVR STEMI. Median time from symptom onset to hospital arrival was longer in non-TAVR patients (180 min [IQR: 120 to $386 \mathrm{~min}$ ] vs. $130 \mathrm{~min}$ [IQR: 60 to $260 \mathrm{~min}$ ]; $\mathrm{p}=0.015$ ), but door-to-balloon time was $33 \%$ higher in TAVR patients (40 min [IQR: 25 to $57 \mathrm{~min}$ ] vs. $30 \mathrm{~min}$ [IQR: 25 to $35 \mathrm{~min}$ ]; $\mathrm{p}=0.003$ ), and $20.8 \%$ versus $8.6 \%$ of patients had a door-to-balloon time $\geq 60 \mathrm{~min}(\mathrm{p}=0.005)$. Similar results were obtained when excluding patients with prior CABG 
TABLE 4 Comparison of Baseline Variables, Clinical Characteristics, and Management of STEMI After TAVR Versus STEMI Without Prior TAVR Managed With Primary PCI

Post-TAVR STEMI

(Primary PCI Cohort)

$(\mathbf{n}=\mathbf{1 0 2})$

Baseline variables

Age, yrs

Female

BMI, $\mathrm{kg} / \mathrm{m}^{2}$

Diabetes mellitus

Hypertension

Dyslipidemia

Current smoking

Atrial fibrillation

COPD

eGFR, $\mathrm{ml} / \mathrm{min}$

Previous CAD

Previous MI

Previous CABG

Previous PAD

Clinical characteristics

ECG findings

Anterior

Inferior

Lateral

LBBB

Other

Killip class

1

2

3

4

Cardiac arrest at admission

LVEF, \%

Antithrombotic medication

before STEMI

None

SAPT

DAPT

OAC

$\mathrm{OAC}+$ antiplatelet

STEMI management

P2 $\mathrm{Y}_{12}$ inhibitor

Clopidogrel

Prasugrel

Ticagrelor

None

Anticoagulant

Unfractionated heparin

Enoxaparin

Bivalirudin

None

GPIIb/IIla inhibitor

Circulatory assist

device

$80.7 \pm 7.6$

47 (46.1)

$27.6 \pm 5.1$

32 (31.4)

$85(83.3)$

$60(58.8)$

14 (13.7)

$26(25.5)$

15 (14.7)

$58.3 \pm 25.2$

71 (69.6)

29 (28.4)

14 (13.7)

23 (22.5)

8 (37.3)

35 (34.3)

5 (4.9)

8 (7.8)

$16(15.7)$

57 (55.9)

23 (22.5)

7 (6.9)

15 (14.7)

$10(9.8)$

$44.7 \pm 14.1$

$2(2.0)$

48 (47.1)

31 (30.4)

8 (7.8)

$13(12.7)$

$59(57.8)$

12 (11.8)

$20(19.6)$

$11(10.8)$

84 (82.4)

2 (2.0)

2 (2.0)

14 (13.7)

8 (7.8)

$2(2.0)$

Values are mean \pm SD or $\mathrm{n}(\%)$.

Abbreviations as in Tables 1 and 2 . $(p=0.034)$. Similarly, procedural time $(p<0.001)$, fluoroscopy time ( $\mathrm{p}<0.001$ ), dose-area product $(\mathrm{p}=0.003)$, and contrast volume $(\mathrm{p}=0.008)$ were higher in patients with prior TAVR (Figure 1). There were no significant differences in treatment delays and procedural performance indexes between valve types but the presence of a self-expanding transcatheter heart valve (vs. balloon-expandable) was associated with a higher fluoroscopy time (20 min [IQR: 12 to $27 \mathrm{~min}$ ] vs. $16 \mathrm{~min}$ [IQR: 9 to $21 \mathrm{~min}$ ]; $\mathrm{p}=0.014$ ) . Nonselective injections were more frequent in patients with prior TAVR for both left and right coronary arteries ( $p<0.001$ for all), and $\geq 2$ catheters were used more frequently to cannulate the right coronary artery (RCA) in patients with prior TAVR $(\mathrm{p}=0.015)$. The proportions of multivessel disease $(p=0.856)$, bifurcation $(\mathrm{p}=0.280)$, ostial lesion $(\mathrm{p}=0.128)$, and calcification $(\mathrm{p}=0.092)$ did not significantly differ between patients with and without prior TAVR. A nonatherothrombotic mechanism was more frequently involved in patients with prior TAVR (17.6\% vs. $4.3 \% ; \mathrm{p}<0.001)$. Definite and possible coronary embolism were considered to be the mechanism of post-TAVR STEMI in $9(8.8 \%)$ and $5(4.9 \%)$ patients, respectively. The coronary embolism was related to the TAVR procedure in 12 patients (the same day of the TAVR procedure in 10 patients, the day after TAVR procedure in 1 patient, and 8 days after TAVR in 1 patient) and to an infective endocarditis at the level of the TAVR bioprosthesis in 2 patients . A late valve migration causing a partial compression of the left sinus of Valsalva and the left main artery by the transcatheter heart valve occurred in 1 patient (2.4\%) 70 days after TAVR (Evolut R system), and it was managed with offpump CABG (left internal mammary artery to left anterior descending and right internal mammary artery to obtuse marginal). Finally, no case of STEMI related to a significant stenosis left untreated before TAVR was reported, but 2 cases of post-TAVR stent thrombosis occurred, and 1 case of stress cardiomyopathy was identified.

PCI failure occurred more frequently in patients with prior TAVR $(16.5 \%$ vs. $3.9 \%$; $p<0.001)$. Furthermore, the use of $\geq 2$ guide catheters, nonselective injection with the guide catheter, and the use of a guide catheter extension were more frequent in TAVR patients ( $\mathrm{p}<0.05$ for all). Individual data from the 14 TAVR patients presenting PCI failure are presented

. Four patients presenting inferior STEMI related to an acute RCA 
occlusion were not revascularized owing to failure to cannulate the RCA despite the use of multiple catheters (CoreValve/Evolut R system: $\mathbf{n}=3$; Sapien XT: 1 patient). One additional patient with an Evolut $\mathrm{R}$ valve system presenting with a left main stenosis was also not revascularized owing to failure to cannulate the left coronary artery. Failure to cross the lesion with the guidewire (not directly related to the transcatheter heart valve) occurred in 4 patients, including 1 patient with coronary embolism related to the TAVR procedure. No reflow occurred in 3 patients, and 1 case of coronary perforation with cardiac tamponade was recorded. Finally, 1 patient died during the procedure before PCI completion.

LATE CLINICAL OUTCOMES. Late outcomes of the whole cohort of patients with post-TAVR STEMI are presented . A total of 50 patients (42.4\%) died at a median follow-up of 7 months (IQR: 1 to 21 months) after STEMI. Overall, the rates of death, stroke, MI, and MACCE after the STEMI were 34.1 per 100 person-years (PY), 6.0 per $100 \mathrm{PY}, 4.9$ per $100 \mathrm{PY}$, and 46.9 per $100 \mathrm{PY}$, respectively (Figure 2). Late outcomes of the subpopulation with post-TAVR STEMI managed with primary PCI are presented in . Overall, the rates of death, stroke, MI, and MACCE after the STEMI were 28.1 per $100 \mathrm{PY}, 4.8$ per $100 \mathrm{PY}, 4.4$ per $100 \mathrm{PY}$, and 38.5 per $100 \mathrm{PY}$, respectively. The factors associated with an increased mortality risk after a post-TAVR STEMI in the primary PCI cohort are presented in Table 6. By multivariable analysis, estimated glomerular filtration rate $<60 \mathrm{ml} / \mathrm{min}$ (hazard ratio [HR]: 3.02; 95\% confidence interval [CI]: 1.42 to $6.43 ; \mathrm{p}=0.004$ ), Killip class $\geq 2$ (HR: $2.74 ; 95 \%$ CI: 1.37 to 5.49 ; $\mathrm{p}=0.004$ ), and PCI failure (HR: 3.23 ; $95 \%$ CI: 1.42 to 7.31; $\mathrm{p}=0.005$ ) determined a higher risk of death. Comparison of clinical outcomes in post-TAVR STEMI versus STEMI without prior TAVR are presented in . Both in-hospital and late outcomes were poorer in patients with post-TAVR STEMI, with an increased incidence of death $(p<0.001)$, stroke $(\mathrm{p}=0.008)$, and MACCE $(\mathrm{p}<0.001)$.

\section{DISCUSSION}

This study is the first to determine the clinical, procedural characteristics, and outcomes of STEMI following TAVR, and the main findings can be summarized as follows: 1) about one-third of STEMI events after TAVR occurred within the few months following the procedure, and a nonatherothrombotic mechanism (coronary embolism, late prosthesis migration) was involved in $\sim 15 \%$ of cases; 2 ) about $85 \%$ of patients were managed with primary PCI; 3 ) in primary PCI patients, prior TAVR was associated with a longer door-to-balloon time and a much higher PCI failure rate, partially due to coronary access issues specific to the TAVR population; and 4) in-hospital and late outcomes following post-TAVR STEMI were poor (in-hospital and 1-year mortality rates up to $25 \%$ and 33\%, respectively), with PCI failure determining an increased risk (Central Illustration).

BASELINE AND STEMI CLINICAL CHARACTERISTICS.OUI study population consisted of intermediate- to highrisk patients who presented with STEMI after TAVR. Unlike patients included in previous TAVR registries (1), patients with post-TAVR STEMI exhibited higher rates of prior CAD (70\% vs. 50\%) and PCI in the preTAVR work-up (39\% vs. 25\%) (1). In fact, a history of CAD and PCI before TAVR had already been identified as independent predictors of ACS after TAVR $(2,4)$. Also, the characteristics of the study population were very different from those reported in general STEMI registries $(12,13)$, with a mean age of $\sim 80$ years and $50 \%$ being women. Furthermore, the rates of hypertension, diabetes mellitus, prior MI, and prior CABG (all common among TAVR patients) were higher than those reported in patients with STEMI without prior TAVR (12-14). This resulted in a much higher comorbidity burden in patients with post-TAVR STEMI managed with primary PCI compared with historical STEMI series and a non-TAVR control cohort.

Of note, patients presenting STEMI after TAVR were frequently in an unstable clinical condition at admission, with $47 \%, 18 \%$, and $11 \%$ of the study population presenting congestive signs, cardiogenic shock, and cardiac arrest, respectively. This finding contrasts with features of all-comers with STEMI (12-14) and is likely related to the advanced age and multiple comorbidities of TAVR recipients. Whereas $<5 \%$ of allcomers with STEMI have a left bundle branch block at the initial ECG $(14,15)$, this feature was present in $8 \%$ of our study population, and a paced rhythm was present in $3 \%$ of patients. Conduction disturbances, which remain the most frequent complication of TAVR (16), may hinder the diagnosis of STEMI, leading to significant treatment delays. Prasugrel and ticagrelor are currently recommended over clopidogrel for $\mathrm{P}_{2} \mathrm{Y}_{12}{ }^{-}$ inhibitor loading in patients with STEMI undergoing primary PCI $(17,18)$. In contrast, most patients in the present study were treated with clopidogrel. The potential increased bleeding risk in TAVR patients, the significant proportion of patients receiving long-term oral anticoagulant ( $20 \%$ ), and the prasugrel contraindication beyond 75 years of age likely explain this discrepancy.

ANGIOGRAPHIC CHARACTERISTICS OF STEMI AFTER TAVR. Coronary angiography and PCI are usually 
TABLE 5 Comparison of Procedural Characteristics of STEMI After TAVR (Primary PCI Cohort) Versus STEMI Without Prior TAVR

\begin{tabular}{|c|c|c|c|}
\hline & $\begin{array}{c}\text { Post-TAVR STEMI } \\
\text { (Primary PCI Cohort) } \\
(\mathrm{n}=102)\end{array}$ & $\begin{array}{l}\text { STEMI Without } \\
\text { Prior TAVR } \\
(n=439)\end{array}$ & p Value \\
\hline $\begin{array}{l}\text { Time from symptom onset to hospital } \\
\text { arrival, min }\end{array}$ & $130(60-260)$ & $180(120-386)$ & 0.015 \\
\hline Time from door to balloon, $\mathrm{min}$ & $40(25-57)$ & $30(25-35)$ & 0.003 \\
\hline Arterial access & & & $<0.001$ \\
\hline Radial & $54(52.9)$ & $397(90.4)$ & \\
\hline Femoral & $48(47.1)$ & $42(9.6)$ & \\
\hline \multicolumn{4}{|l|}{ Left coronary artery } \\
\hline$\geq 2$ catheters used & $6(5.9)$ & $18(4.1)$ & 0.431 \\
\hline Nonselective injection & $23(22.5)$ & $5(1.1)$ & $<0.001$ \\
\hline \multicolumn{4}{|l|}{ Right coronary artery } \\
\hline$\geq 2$ catheters used & $11(10.8)$ & $20(4.6)$ & 0.015 \\
\hline Nonselective injection & $25(24.5)$ & $14(3.2)$ & $<0.001$ \\
\hline Procedural time, min & $46(37-69)$ & $36(25-49)$ & $<0.001$ \\
\hline Fluoroscopy time, min & $18.3(10.1-24.5)$ & $10.1(6.4-16.0)$ & $<0.001$ \\
\hline Dose-area product, $\mathrm{cGy} \times \mathrm{cm}^{2}$ & $7,609(3,600-13,500)$ & $4,637(2,741-7,781)$ & 0.003 \\
\hline Contrast volume, $\mathrm{ml}$ & $170(120-130)$ & $146(110-185)$ & 0.008 \\
\hline Bleeding complication & $7(6.9)$ & $36(8.2)$ & 0.653 \\
\hline \multicolumn{4}{|l|}{ Angiogram findings } \\
\hline Number vessels disease & & & 0.856 \\
\hline 0 & $3(2.9)$ & $10(2.3)$ & \\
\hline 1 & $59(57.8)$ & $245(55.8)$ & \\
\hline 2 & $27(26.5)$ & $114(26.0)$ & \\
\hline 3 & $13(12.8)$ & $70(15.9)$ & \\
\hline Culprit lesion & & & $<0.001$ \\
\hline LM & $9(8.8)$ & $6(1.4)$ & \\
\hline LAD & $38(37.3)$ & $176(40.1)$ & \\
\hline LCX & $12(11.8)$ & $57(13.0)$ & \\
\hline RCA & $32(31.4)$ & $187(42.6)$ & \\
\hline RIMA & $1(1.0)$ & $0(0.0)$ & \\
\hline SVG & $4(3.9)$ & $3(0.7)$ & \\
\hline None & $6(5.9)$ & $10(2.3)$ & \\
\hline Atherothrombotic mechanism & $84(82.4)$ & $420(95.7)$ & $<0.001$ \\
\hline Other mechanisms & & & - \\
\hline Stent thrombosis & $2(2.0)$ & $3(0.7)$ & \\
\hline In-stent restenosis & $0(0.0)$ & $2(0.5)$ & \\
\hline SCAD & $0(0.0)$ & $2(0.5)$ & \\
\hline Coronary spasm & $0(0.0)$ & $1(0.2)$ & \\
\hline Definite embolism & $9(8.8)$ & $1(0.2)$ & \\
\hline Possible embolism & $5(4.9)$ & $0(0.0)$ & \\
\hline Late valve migration & $1(1.0)$ & $0(0.0)$ & \\
\hline Stress cardiomyopathy & $1(1.0)$ & $10(2.3)$ & \\
\hline TIMI flow grade & & & 0.016 \\
\hline 0 & $56(54.9)$ & 298 (67.9) & \\
\hline 1 & $11(10.8)$ & $24(5.5)$ & \\
\hline 2 & $19(18.6)$ & $46(10.5)$ & \\
\hline 3 & $16(15.7)$ & $71(16.2)$ & \\
\hline$\%$ stenosis & $94.2 \pm 11.6$ & $96.8 \pm 7.0$ & 0.039 \\
\hline Bifurcation & $14(13.7)$ & $80(18.2)$ & 0.280 \\
\hline Ostial lesion & 20 (19.6) & $60(13.7)$ & 0.128 \\
\hline Calcifications & 19 (18.6) & $54(12.3)$ & 0.092 \\
\hline Thrombus & $79(77.5)$ & $360(82.0)$ & 0.290 \\
\hline CA without $\mathrm{PCl}$ attempted & $17(16.7)$ & $25(5.7)$ & $<0.001$ \\
\hline
\end{tabular}

Continued on the next page performed in $99 \%$ and $90 \%$ of patients with STEMI, respectively (12). In the present study, the proportion of patients who did not undergo coronary angiography and PCI was notably high $(13 \%$ and $27 \%$, respectively), and these findings were in line with previous studies regarding post-TAVR ACS $(3,4)$. The decision not to perform coronary angiography was based on resuscitation failure, critical medical situations with altered general condition or high comorbidity burden, and late presentation. In fact, coronary angiography and PCI are less likely to be performed as the patients' age increase (5), and elderly patients are commonly under-represented in STEMI registries (12-14). Thus, the advanced age along with the high comorbidity burden of current TAVR recipients would likely explain the high rate of medical management versus an invasive strategy. Future studies further evaluating the low rate of invasive procedures in this population are warranted.

A coronary embolism was considered to be responsible for the STEMI in a significant proportion $(14 \%)$ of cases, and one-half of them were not revascularized (revascularization not attempted or PCI failed). The absence of strong criteria for a definite diagnosis of coronary embolism (11) and the higher likelihood of a STEMI event within the few months following TAVR raise the question of a possible underestimation of the real frequency of such mechanism in post-TAVR STEMI. Further studies with systematic intracoronary imaging and anatomopathologic examination of the thrombus are required to better determine the incidence of coronary embolism in STEMI following TAVR. One case of late valve migration compressing the left main artery requiring CABG was identified in the present study. Delayed coronary occlusion is a rare complication of TAVR (incidence of $0.22 \%$ ), occurs more commonly after valve-in-valve procedures (particularly with selfexpanding transcatheter valves), and is associated with a high in-hospital mortality (19). Late valve migration may also have been involved in some patients with early post-TAVR STEMI who died before undergoing coronary angiography.

PROCEDURAL CHARACTERISTICS OF STEMI AFTER TAVR. Treatment delays are a simple index of quality of care in STEMI, and their reduction has been associated with a significant decrease in myocardial damage and improved outcomes $(17,20)$. In the present study, the median time from symptom onset to hospital arrival was shorter in patients with prior TAVR, likely explained by a greater tendency of TAVR patients to go to the hospital (high comorbidity 
burden). On the other hand, the mean door-toballoon time was 33\% higher in patients with prior TAVR. Furthermore, higher rates of unselective injection, need of $\geq 2$ catheters to cannulate the coronary ostia, and guide catheter extension use were also observed among patients presenting with STEMI after TAVR. All of these aspects are indirect evidence of increased complexity when an emergency PCI has to be performed in a STEMI patient with prior TAVR. This likely contributed to delayed PCI times and negatively affected the clinical outcomes of STEMI after TAVR. In addition, the decision to perform a primary PCI may have been delayed in some cases on the basis of high comorbidity burden and atypical clinical presentation.

The rate of PCI failure was much higher in patients with prior TAVR $(\sim 15 \%)$ compared with the control (non-TAVR) cohort (4\%) and was also markedly higher than the $6 \%$ rate usually reported in allcomer primary PCI patients (13). The reason for PCI failure was directly related to the transcatheter prosthesis in one-half of the patients, mainly owing to coronary access issues. Of note, lesion complexity was similar between patients with and without prior TAVR (as evidenced by the similar proportion of multivessel disease, bifurcation, ostial location, and calcifications). This finding further supports the hypothesis that the increased revascularization time and the higher proportion of failed PCI in TAVR patients were not related to lesion complexity discrepancies, but rather to an extrinsic factor (coronary access difficulties resulting from interaction between the transcatheter heart valve and the coronary ostia in this instance). Femoral access has been proposed to facilitate PCI after TAVR (21). In the present study, this approach was selected in one-half of the cases, and a widespread use of femoral access could contribute to reduce door-toballoon time and PCI failure rate in patients presenting with STEMI after TAVR. Furthermore, a better understanding of the potential difficulties of coronary cannulation caused by the presence of a transcatheter heart valve, as well as techniques for enhancing coronary access, could improve PCI efficiency and outcomes of patients with post-TAVR STEMI. The fact that many patients with postTAVR STEMI may be directed to and treated in centers with no TAVR experience further highlights the importance of establishing clear recommendations and standardized practices in this setting.

In this study, PCI failure related to coronary cannulation failure occurred in 5 patients. CoreValve/ Evolut devices represented $49 \%$ of all implanted transcatheter heart valves, but $80 \%$ of PCI failures

\begin{tabular}{|c|c|c|c|}
\hline & $\begin{array}{c}\text { Post-TAVR STEMI } \\
\text { (Primary PCI Cohort) } \\
\text { (n=102) }\end{array}$ & $\begin{array}{l}\text { STEMI Without } \\
\text { Prior TAVR } \\
(n=439)\end{array}$ & p Value \\
\hline \multicolumn{4}{|l|}{ Reason for $\mathrm{PCl}$ not attempted } \\
\hline Emergency CABG & $1(1.0)$ & $5(1.1)$ & \\
\hline MINOCA & $6(5.9)$ & $10(2.3)$ & \\
\hline SCAD & $0(0.0)$ & $1(0.2)$ & \\
\hline Coronary spasm & $0(0.0)$ & $1(0.2)$ & \\
\hline $\begin{array}{l}\text { High thrombotic burden with TIMI } \\
\text { flow grade } 3\end{array}$ & $2(2.0)$ & $3(0.7)$ & \\
\hline Distal lesion & $4(3.9)$ & $0(0.0)$ & \\
\hline $\begin{array}{l}\text { Absolute contraindication to } \\
\text { antiplatelet therapy }\end{array}$ & $1(1.0)$ & $0(0.0)$ & \\
\hline Delayed PCl* & $1(1.0)$ & $1(0.2)$ & \\
\hline Evolved STEMI $(>12 \mathrm{~h}) \dagger$ & $2(2.0)$ & $2(0.5)$ & \\
\hline Cardiac arrest with pulseless activity & $0(0.0)$ & $2(0.5)$ & \\
\hline \multicolumn{4}{|l|}{$\mathrm{PCl}$ characteristics } \\
\hline$\geq 2$ left guide catheters used & $4(7.7)$ & $5(2.2)$ & 0.042 \\
\hline$\geq 2$ right guide catheters used & $6(20.0)$ & $13(7.1)$ & 0.022 \\
\hline Nonselective injection & $18(21.2)$ & $10(2.4)$ & $<0.001$ \\
\hline Guide catheter extension & $9(10.6)$ & $15(3.6)$ & 0.006 \\
\hline Thrombectomy & $17(20.0)$ & $136(32.9)$ & 0.019 \\
\hline Pre-dilatation & $58(68.2)$ & $255(61.6)$ & 0.249 \\
\hline Cutting balloon & $1(1.2)$ & $1(0.2)$ & 0.214 \\
\hline Rotational atherectomy & $1(1.2)$ & $1(0.2)$ & 0.214 \\
\hline Number of stents implanted & $0.9 \pm 0.8$ & $1.4 \pm 0.8$ & $<0.001$ \\
\hline Stented length, mm & $24.4 \pm 12.2$ & $31.7 \pm 18.7$ & $<0.001$ \\
\hline Stent diameter, mm & $3.2 \pm 0.5$ & $3.2 \pm 0.5$ & 0.906 \\
\hline Device used & & & $<0.001$ \\
\hline DES & $50(58.8)$ & $322(77.8)$ & \\
\hline BMS & $8(9.4)$ & $73(17.6)$ & \\
\hline DEB & $3(3.5)$ & $1(0.2)$ & \\
\hline POBA & $10(11.8)$ & $10(2.4)$ & \\
\hline None & $14(16.5)$ & $8(1.9)$ & \\
\hline Post-dilation TIMI flow grade & & & $<0.001$ \\
\hline 0 & $11(13.0)$ & $7(1.7)$ & \\
\hline 1 & $3(3.5)$ & $6(1.5)$ & \\
\hline 2 & $3(3.5)$ & $25(6.0)$ & \\
\hline 3 & $68(80.0)$ & $376(90.8)$ & \\
\hline $\mathrm{PCl}$ failure & $14(16.5)$ & $16(3.9)$ & $<0.001$ \\
\hline \multicolumn{4}{|l|}{ Reason for $\mathrm{PCl}$ failure } \\
\hline Failure to cannulate coronary ostium & $5(5.9)$ & $0(0.0)$ & \\
\hline Failure to cross lesion & $4(4.7)$ & $2(0.5)$ & \\
\hline No-reflow & $3(3.5)$ & $12(2.9)$ & \\
\hline Coronary perforation & $1(1.2)$ & $2(0.5)$ & \\
\hline Procedural death & $1(1.2)$ & $0(0.0)$ & \\
\hline Complete revascularization & $51(60.0)$ & $297(71.7)$ & 0.032 \\
\hline Culprit lesion revascularization only & $74(87.1)$ & $385(93.0)$ & 0.068 \\
\hline
\end{tabular}

Values are median (interquartile range), $\mathrm{n}(\%)$, or mean \pm SD. *Cases where $\mathrm{PCI}$ was postponed due to coronary angiogram findings. TSTEMI with chest pain evolving for more than $12 \mathrm{~h}$ with deep Q-wave.

BMS = bare-metal stent; DEB = drug-eluting balloon; DES = drug-eluting stent; LAD = left anterior descending; $L C X=$ left circumflex; $L M=$ left main; MINOCA = myocardial infarction with nonobstructive coronary arteries; POBA = plain old balloon angioplasty; RCA = right coronary artery; RIMA = right internal mammary artery; SCAD = spontaneous coronary artery dissection; SVG = saphenous vein graft; TIMI = Thrombosis in Myocardial Infarction; other abbreviations as in Tables 1 and 2.

involved these devices. Similarly, the culprit lesion was located in the RCA in $31 \%$ of cases, but $80 \%$ of failed cannulations were related to RCA. This finding, combined with the high rate of unselective injection, 
FIGURE 1 Comparison of Median Time From Symptom Onset to Hospital Arrival, Time From Door to Balloon, Procedural Time, Fluoroscopy Time, Dose-Area Product, and Contrast Volume Between Patients With and Without TAVR

A

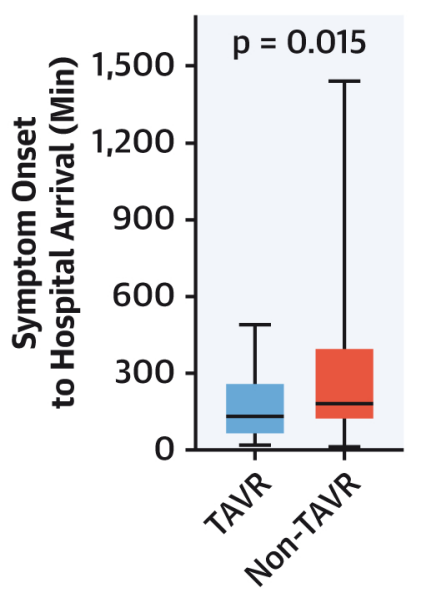

D

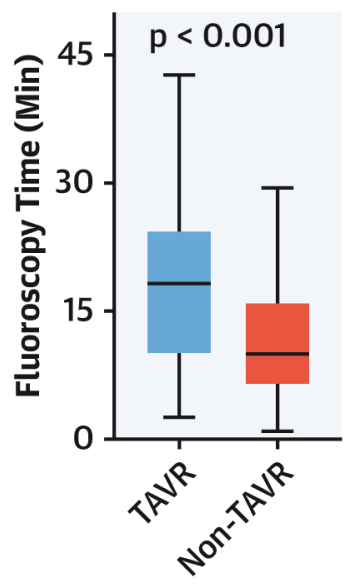

B

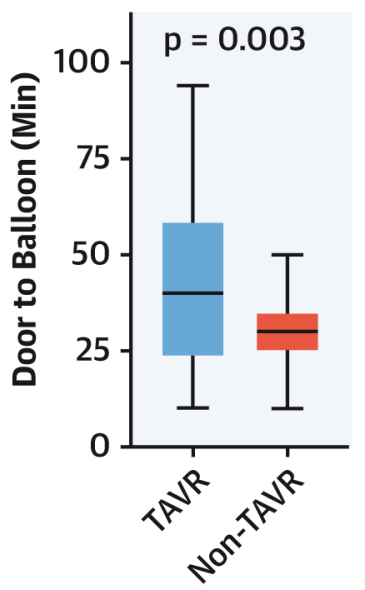

E

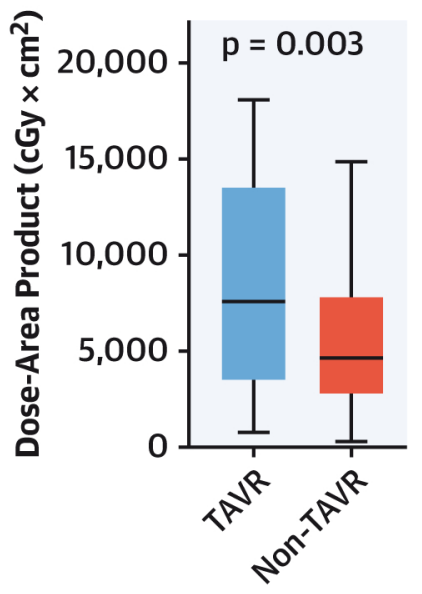

C

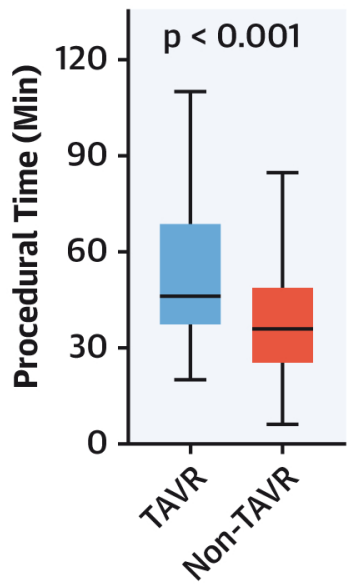

$\mathbf{F}$

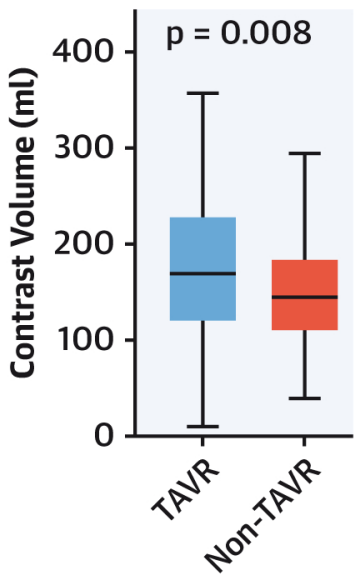

(A) Time from symptom onset to hospital arrival; (B) time from door to balloon; (C) procedural time; (D) fluoroscopy time; (E) dose-area product; (F) contrast volume. The boxes represents the median with interquartile ranges, and the whiskers represent the upper and lower limits excluding the extreme values (Tukey style). TAVR = transcatheter aortic valve replacement.

the frequent need for $\geq 2$ guide catheters to adequately cannulate the RCA, and the longer fluoroscopy time in patients with self-expanding devices further suggests increased coronary access difficulties through this type of self-expanding valve systems, especially for the RCA cannulation $(6,22,23)$. However, this should be interpreted with caution given the small number of events. Finally, the relatively high rate of conduction disturbances after TAVR (16), along with their negative clinical impact (24), has led some operators to minimize implantation depth (25). Implantation depth is also a strong determinant of coronary access issues after TAVR (23), and the optimal implantation position should take into account both the risk of conduction disturbances and coronary access after TAVR, particularly in low-risk TAVR recipients with longer life expectancy.

CLINICAL OUTCOMES OF STEMI AFTER TAVR. Compared with data from STEMI registries (12-14), patients presenting with STEMI after TAVR exhibited a much higher rate of adverse events and a very high in-hospital and late mortality. Also, these outcomes were worse than those observed in elderly patients presenting with ACS (5). This discrepancy may be explained by several factors. First, the long door-toballoon times along with very high rates of PCI failure: PCI failure was strongly associated with post- 
FIGURE 2 Kaplan-Meier Curves for Clinical Events After STEMI Following TAVR (Whole Cohort)

A

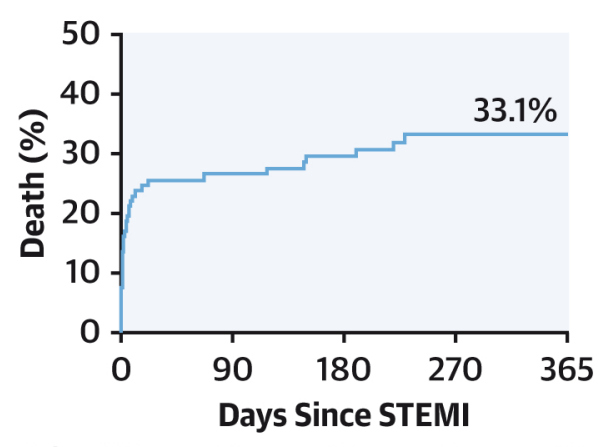

B

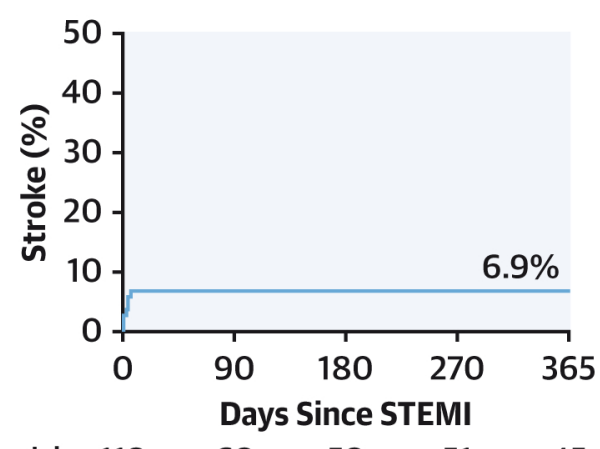

Patients at risk: $118 \quad 75 \quad 63 \quad 55 \quad 49$

C

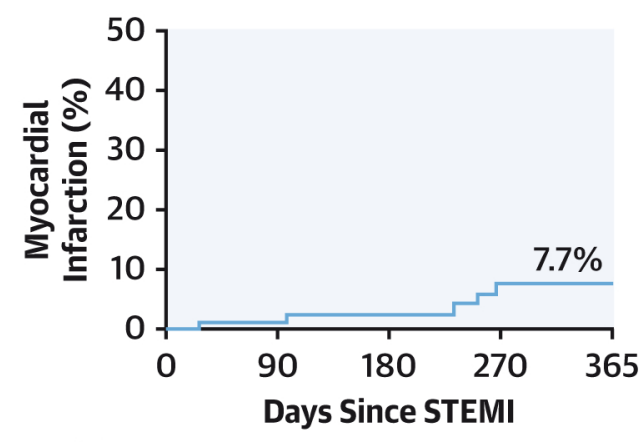

Patients at risk: $\begin{array}{lllll}118 & 68 & 58 & 51 & 45\end{array}$
D

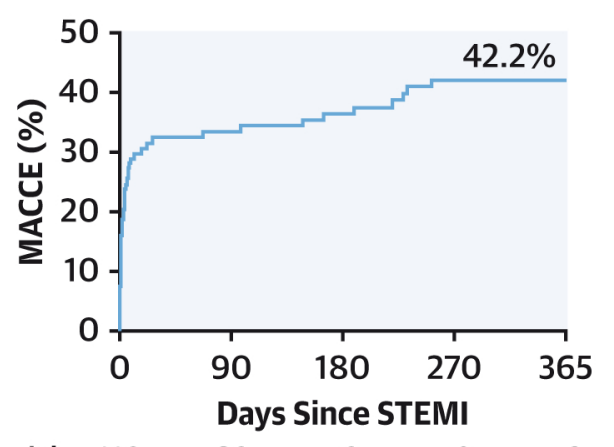

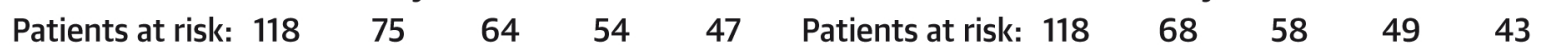

(A) All-cause death; (B) stroke; (C) myocardial infarction; (D) major adverse cardiovascular event (MACCE). STEMI = ST-segment elevation myocardial infarction; TAVR = transcatheter aortic valve replacement.

STEMI mortality, and a trend toward an increased risk of death among patients with longer door-to-balloon times was also observed. Second, the clinical characteristics of current TAVR recipients (elderly patients with high comorbidity burden) and the left ventricle changes associated with aortic stenosis also may have contributed to the poorer outcomes compared with all-comers with ACS/STEMI. The high proportion of post-TAVR STEMI patients in an unstable clinical condition, combined with the negative impact of Killip class $\geq 2$, supports the latter hypothesis. Finally, alternative pathophysiologic mechanisms, such as coronary embolism and late valve migration (causing delayed coronary occlusion), could have complicated revascularization or led to rapid death in some cases. In the present study, no significant impact of nonatherothrombotic mechanism on outcomes was observed, but a larger sample size would be necessary to demonstrate a potential association between the pathophysiologic mechanism and clinical outcomes.
STUDY LIMITATIONS. This study was performed in intermediate- to high-risk patients, and the findings may not apply to lower-risk populations with TAVR. Coronary embolism was found to be responsible for STEMI in a significant proportion of patients, but this entity suffers from a lack of consensual definition, and no adjudication committee was available in this study. The control cohort was obtained from a selected group of centers. However, the results of primary PCI in allcomer (non-TAVR) patients were obtained during the same period of time as in post-TAVR STEMI patients and were similar to those reported in other contemporary STEMI studies $(12,13)$, suggesting an appropriate representability of this control group.

\section{CONCLUSIONS}

STEMI following TAVR is a rare event but associated with dismal in-hospital and midterm clinical outcomes. Longer door-to-balloon times and a higher PCI failure rate were observed in TAVR patients, partially 
TABLE 6 Factors Associated With Death After a STEMI Following TAVR (Primary PCl Cohort)

\begin{tabular}{|c|c|c|c|c|}
\hline & \multicolumn{2}{|c|}{ Univariable model } & \multicolumn{2}{|c|}{ Multivariable model } \\
\hline & HR $(95 \% \mathrm{Cl})$ & p Value & HR $(95 \% \mathrm{Cl})$ & $p$ Value \\
\hline Age (per 1-yr increase) & $1.00(0.96-1.04)$ & 0.948 & - & - \\
\hline Female & $1.01(0.52-1.96)$ & 0.980 & - & - \\
\hline Diabetes mellitus & $1.39(0.72-2.70)$ & 0.329 & - & - \\
\hline Hypertension & $1.03(0.43-2.47)$ & 0.948 & - & - \\
\hline eGFR $<60 \mathrm{ml} / \mathrm{min}$ & $2.88(1.35-6.11)$ & 0.006 & $3.02(1.42-6.43)$ & 0.004 \\
\hline COPD & $0.98(0.42-2.27)$ & 0.964 & - & - \\
\hline Atrial fibrillation & $0.85(0.40-1.80)$ & 0.674 & - & - \\
\hline Prior CAD & $1.05(0.51-2.16)$ & 0.904 & - & - \\
\hline Prior PAD & $1.99(0.99-4.01)$ & 0.053 & - & - \\
\hline $\begin{array}{l}\text { Self-expanding THV } \\
\text { (vs. balloon- or } \\
\text { mechanically } \\
\text { expandable) }\end{array}$ & $0.98(0.51-1.85)$ & 0.937 & - & - \\
\hline $\begin{array}{l}\text { Anterior STEMI (vs. } \\
\text { other localization) }\end{array}$ & $1.42(0.75-2.72)$ & 0.285 & - & - \\
\hline Killip class $\geq 2$ & $2.56(1.29-5.07)$ & 0.007 & $2.74(1.37-5.49)$ & 0.004 \\
\hline $\begin{array}{l}\text { Nonatherothrombotic } \\
\text { mechanism }\end{array}$ & $0.66(0.26-1.71)$ & 0.393 & - & - \\
\hline $\begin{array}{l}\text { Time from door to } \\
\text { balloon }>60 \mathrm{~min}\end{array}$ & $2.10(0.81-5.44)$ & 0.125 & - & - \\
\hline $\mathrm{PCl}$ failure & $2.70(1.22-5.99)$ & 0.015 & $3.23(1.42-7.31)$ & 0.005 \\
\hline
\end{tabular}

THV $=$ transcatheter heart valve; other abbreviations as in Tables 1 and 2. due to coronary access issues specific to the TAVR population, and PCI failure was strongly associated with an increased mortality risk. These results highlight the urgent need for a better understanding of coronary cannulation difficulties and the techniques for enhancing coronary access and improving PCI success rates and clinical outcomes in this population. Also, further studies are required to better determine the role of nonatherothrombotic mechanisms (coronary embolism, late valve migration) among patients with STEMI after TAVR.

\section{FUNDING SUPPORT AND AUTHOR DISCLOSURES}

Dr. Faroux has received fellowship support from Institut Servier and the Association Régionale de Cardiologie de Champagne-Ardenne (ARCCA); and has received research grants from Biotronik, Edwards Lifesciences, and Medtronic. Dr. Abdel-Wahab has served as a consultant for Boston Scientific and Medtronic. Dr. Windecker has received research and educational grants from Abbott, Amgen, BMS, Bayer, Boston Scientific, Biotronik, Cardinal Health, CardioValve, CSL Behring, Daiichi-Sankyo, Edwards Lifesciences, Johnson \& Johnson, Medtronic, Querbet, Polares, Sanofi, Terumo, and Sinomed. Dr. Auffret has received lecture fees from Edwards Lifesciences and Medtronic. Dr. Trillo-Nouche has served as a proctor for Boston Scientific and Medtronic. Dr. Toggweiler has served as a consultant and proctor for Abbott, Boston Scientific, Biosensors, and Medtronic. Dr. Tarantini has received lecture fees from Boston Scientific, Edwards Lifesciences, Gada, and Medtronic. Dr. Saia has served as a member of advisory

CENTRAL ILLUSTRATION ST-Segment Elevation Myocardial Infarction Following Transcatheter Aortic Valve Replacement

\section{STEMI Following TAVR}

\section{- $33 \%$ longer door-to -balloon time}

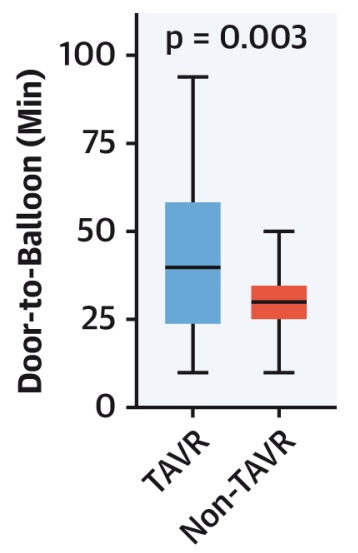

\section{- 4-fold higher \\ $\mathrm{PCl}$ failure rate}

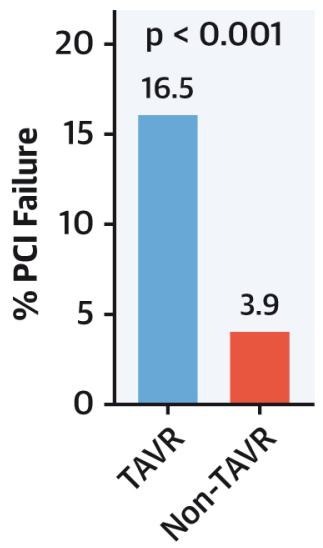

- Poor clinical outcomes

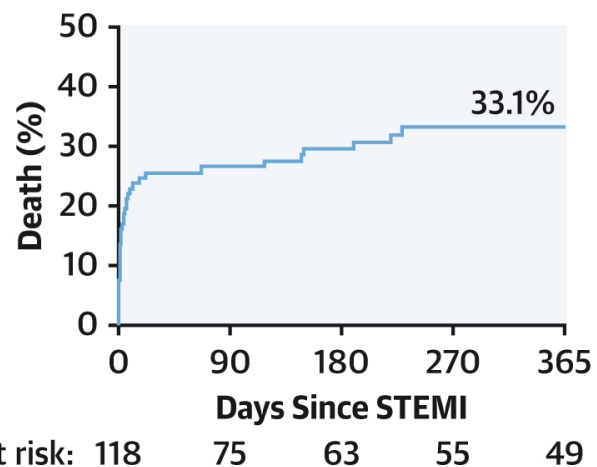

Faroux, L. et al. J Am Coll Cardiol. 2021;77(17):2187-99.

(Left panel) Time from door to balloon (TAVR and non-TAVR primary PCI patients); (Mid panel) PCI failure rate (TAVR and non-TAVR primary PCI patients); (Right panel) Time-to-event curve for all-cause death (STEMI post-TAVR patients, whole cohort). $\mathrm{PCl}$ = percutaneous coronary intervention; STEMI = ST-segment elevation myocardial infarction; TAVR $=$ transcatheter aortic valve replacement. 
boards for Abbott, Edwards Lifesciences, and Medtronic. Dr. Durand has served as a consultant for Edwards Lifesciences. Dr. Asmarats has served as a proctor for Abbott. Dr. Nejjari has served as a proctor for Abbott and Boston Scientific. Dr. Muntané-Carol was supported by a grant from the Fundación Alfonso Martín Escudero (Madrid, Spain). Dr. Mangieri has received an institutional grant from Boston Scientific. Dr. Rodés-Cabau has received institutional research grants from Edwards Lifesciences, Medtronic, and Boston Scientific; and holds the Research Chair "Fondation Famille Jacques Larivière" for the Development of Structural Heart Disease Interventions. All other authors have reported that they have no relationships relevant to the contents of this paper to disclose.

ADDRESS FOR CORRESPONDENCE: Dr. Josep RodésCabau, Quebec Heart and Lung Institute, Laval University, 2725 Chemin Ste-Foy, Québec City, Québec G1V4G5, Canada. E-mail: josep.rodes@criucpq.ulaval.ca. Twitter: @IUCPQ.

\section{PERSPECTIVES}

\section{COMPETENCY IN PATIENT CARE AND PROCEDURAL}

SKILLS: STEMI events occur usually within the few months post-TAVR, and nonatherothrombotic mechanisms are involved in $\sim 15 \%$ of cases. Longer door-to-balloon times and a higher $\mathrm{PCI}$ failure rate may be partially attributed to coronary access challenges specific to the TAVR setting, and PCI failure is associated with an increased risk of mortality.

TRANSLATIONAL OUTLOOK: Further studies are needed to develop better techniques for coronary access and improve clinical outcomes in this population.

\section{REFERENCES}

1. Faroux L, Guimaraes L, Wintzer-Wehekind J, et al. Coronary artery disease and transcatheter aortic valve replacement: JACC state-of-the-art review. J Am Coll Cardiol 2019;74:362-72.

2. Vilalta $V$, Asmarats $L$, Ferreira-Neto $A N$, et al. Incidence, clinical characteristics, and impact of acute coronary syndrome following transcatheter aortic valve replacement. J Am Coll Cardiol Intv 2018;11:2523-33.

3. Faroux L, Munoz-Garcia E, Serra V, et al. Acute coronary syndrome following transcatheter aortic valve replacement. Circ Cardiovasc Interv 2020;13: e008620

4. Mentias A, Desai MY, Saad M, et al. Incidence and outcomes of acute coronary syndrome after transcatheter aortic valve replacement. J Am Coll Cardiol Intv 2020;13:938-50.

5. Avezum $A$, Makdisse M, Spencer $F$, et al. Impact of age on management and outcome of acute coronary syndrome: observations from the Global Registry of Acute Coronary Events (GRACE). Am Heart J 2005;149:67-73.

6. Couture T, Faroux L, Junquera $L$, et al. Interaction between self-expanding transcatheter heart valves and coronary ostia: an angiographically based analysis of the Evolut R/Pro valve system. J Invasive Cardiol 2020;32:123-8

7. Faroux L, Couture T, Guimaraes C, et al. Interaction between balloon-expandable valves and coronary ostia: angiographic analysis and impact on coronary access. J Invasive Cardiol 2020;32: $235-42$.

8. Saia $F$, Palmerini $T$, Compagnone $M$, et al. Coronary artery disease and reasonably incomplete coronary revascularization in high-risk patients undergoing transcatheter aortic valve implantation. Catheter Cardiovasc Interv 2020; $95: 19-27$.

9. Kappetein AP, Head $S J$, Généreux $P$, et al. Updated standardized end point definitions for transcatheter aortic valve implantation: the Valve Academic Research Consortium-2 consensus document. J Am Coll Cardiol 2012;60:1438-54.
10. Thygesen $K$, Alpert JS, Jaffe AS, et al. Fourth universal definition of myocardial infarction (2018). Circulation 2018;138:e618-51.

11. Raphael $C E$, Heit JA, Reeder GS, et al. Coronary embolus: an underappreciated cause of acute coronary syndromes. J Am Coll Cardiol Intv 2018; 11:172-80.

12. Puymirat $E$, Simon $T$, Cayla $G$, et al. Acute myocardial infarction: changes in patient characteristics, management, and 6-month outcomes over a period of 20 years in the FAST-MI program (French Registry of Acute ST-Elevation or Non-STElevation Myocardial Infarction) 1995 to 2015. Circulation 2017;136:1908-19.

13. Rathod KS, Jain AK, Firoozi S, et al. Outcome of inter-hospital transfer versus direct admission for primary percutaneous coronary intervention: an observational study of 25,315 patients with STelevation myocardial infarction from the London Heart Attack Group. Eur Heart J Acute Cardiovasc Care 2020;9:948-57.

14. Park J, Choi KH, Lee JM, et al. Prognostic implications of door-to-balloon time and onset-todoor time on mortality in patients with STsegment-elevation myocardial infarction treated with primary percutaneous coronary intervention. J Am Heart Assoc 2019;8:e012188.

15. Belle L, Cayla G, Cottin Y, et al. French Registry on Acute ST-Elevation and Non-ST-Elevation Myocardial Infarction 2015 (FAST-MI 2015). Design and baseline data. Arch Cardiovasc Dis 2017;110:366-78.

16. Auffret V, Puri R, Urena M, et al. Conduction disturbances after transcatheter aortic valve replacement: current status and future perspectives. Circulation 2017;136:1049-69.

17. Ibanez B, James S, Agewall S, et al. 2017 ESC guidelines for the management of acute myocardial infarction in patients presenting with ST-segment elevation: the Task Force for the Management of Acute Myocardial Infarction in Patients Presenting With ST-Segment Elevation of the European Society of Cardiology (ESC). Eur Heart J 2018;39:119-77.
18. Levine GN, Bates ER, Bittl JA, et al. 2016 ACC/ AHA guideline focused update on duration of dual antiplatelet therapy in patients with coronary artery disease. J Am Coll Cardiol 2016;68:1082-115.

19. Jabbour RJ, Tanaka $A$, Finkelstein $A$, et al. Delayed coronary obstruction after transcathete aortic valve replacement. J Am Coll Cardiol 2018; 71:1513-24

20. Foo $\mathrm{CY}$, Bonsu KO, Nallamothu BK, et al. Coronary intervention door-to-balloon time and outcomes in ST-elevation myocardial infarction: a meta-analysis. Heart 2018;104:1362-9.

21. Yudi $M B$, Sharma $S K$, Tang GHL, Kini A. Coronary angiography and percutaneous coronary intervention after transcatheter aortic valve replacement. J Am Coll Cardiol 2018;71:1360-78.

22. Ochiai $\mathrm{T}$, Chakravarty $\mathrm{T}$, Yoon $\mathrm{SH}$, et al. Coronary access after TAVR. J Am Coll Cardiol Intv 2020;13:693-705.

23. Barbanti M, Costa G, Picci A, et al. Coronary cannulation after transcatheter aortic valve replacement: the RE-ACCESS study. J Am Coll Cardiol Intv 2020;13:2542-55.

24. Faroux L, Chen S, Muntané-Carol G, et al. Clinical impact of conduction disturbances in transcatheter aortic valve replacement recipients: a systematic review and meta-analysis. Eur Heart J 2020;41:2771-81.

25. Jilaihawi $H$, Zhao $Z$, Du $R$, et al. Minimizing permanent pacemaker following repositionable self-expanding transcatheter aortic valve replacement. J Am Coll Cardiol Intv 2019;12:1796-807.

KEY WORDS acute coronary syndrome, mortality, percutaneous coronary intervention, ST-segment elevation myocardial infarction, transcatheter aortic valve replacement 